\title{
Psychometric validation of the Clinical Impairment Assessment in a UK eating disorder service
}

Article

Accepted Version

Creative Commons: Attribution-Noncommercial-No Derivative Works 4.0

Jenkins, P. E. (2013) Psychometric validation of the Clinical Impairment Assessment in a UK eating disorder service. Eating Behaviors, 14 (2). pp. 241-243. ISSN 1471-0153 doi: https://doi.org/10.1016/j.eatbeh.2012.12.001 Available at https://centaur.reading.ac.uk/76102/

It is advisable to refer to the publisher's version if you intend to cite from the work. See Guidance on citing.

Published version at: http://dx.doi.org/10.1016/j.eatbeh.2012.12.001

To link to this article DOI: http://dx.doi.org/10.1016/j.eatbeh.2012.12.001

Publisher: Elsevier

All outputs in CentAUR are protected by Intellectual Property Rights law, including copyright law. Copyright and IPR is retained by the creators or other copyright holders. Terms and conditions for use of this material are defined in the End User Agreement.

www.reading.ac.uk/centaur

\section{CentAUR}


Central Archive at the University of Reading

Reading's research outputs online 
Psychometric validation of the Clinical Impairment Assessment in a UK eating disorders service

\author{
Paul E. Jenkins ${ }^{\mathrm{a}, \mathrm{b}}$
}

${ }^{\text {a} H a m p s h i r e ~ E a t i n g ~ D i s o r d e r s ~ S e r v i c e, ~} 9$ Bath Road, Bitterne, Southampton, Hampshire, UK. SO19 5ES

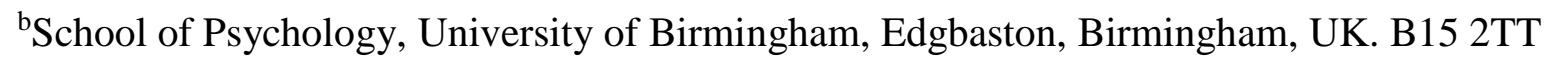

Correspondence should be addressed to: Paul E. Jenkins, D.Clin.Psychol.; Cotswold House Eating Disorders Service, Warneford Hospital, Old Road, Headington, Oxford, OX3 7JX, United Kingdom. Tel: +44 (0)1865 7388 47, Fax: +44 (0)1865 7388 48, E-mail: pej106@gmail.com 


\begin{abstract}
A number of studies have provided data on young women for the Clinical Impairment Assessment (CIA, v. 3.0), a measure of psychosocial impairment in eating disorders. However, little data exists on eating disorder samples. The aim of the current study was to investigate psychometric properties of the CIA in a clinical sample, using confirmatory factor analysis based on the originally-proposed model. The CIA was administered alongside the Eating Disorder Examination (EDE) to 190 individuals referred to an eating disorders service. Psychometric properties of the CIA were acceptable, based on model fit and factor loadings. The CIA appears to be a useful and valid measure for the assessment of impairment in eating disorders.
\end{abstract}

Keywords: Eating disorder; psychometrics; clinical impairment 


\section{Psychometric validation of the Clinical Impairment Assessment in a UK eating disorders service}

\section{Introduction}

The Clinical Impairment Assessment (CIA; Bohn \& Fairburn, 2008) was developed as a measure of functional impairment resulting from eating disorder (ED) symptomatology, and to address shortcomings in existing measures of ED-specific quality of life (EDQoL) (Bohn et al., 2008; see also Engel et al., 2009). A number of recent studies have since looked at psychometric properties of the measure, following data on the original clinical sample reported by the instrument's developers (Bohn et al., 2008).

Data have been provided on Norwegian students (Reas, Rø, Kapstad, \& Lask, 2010), and another 'high risk' sample of college-age women (Vannucci et al., 2012). Two additional studies have been reported; one providing normative data from a Swedish population study (Welch, Birgegård, Parling, \& Ghaderi, 2011), and another by Becker et al. (2010) on Fijian adolescents. However, both studies used translated and adapted versions of the measure and did not include any assessment of the CIA's factor structure. Only the original study of the CIA (Bohn et al., 2008) has investigated psychometric properties in a clinical ED sample, but this was limited by inclusion of only those individuals enrolled in a large-scale cognitive behaviour therapy trial. Therefore, it is not yet known how well the measure performs on a more typical sample of ED patients.

Results from these studies have provided support for the use of the CIA, and have supported the original factor structure of the measure. For interpretation, a total score ('global CIA score') can be calculated giving an overall index of EDQoL, and three subscales - termed 'personal', 'social', and 'cognitive' - can also be computed, with higher scores indicating greater impairment. The original factor structure of the CIA (Bohn et al., 2008) has typically been upheld, although Reas et al. (2010), using exploratory factor analysis (EFA), suggested that one item ("Interfered with your relationships with others") loaded on to a different factor than that suggested by the developers. Psychometric data so far are good, with acceptable levels of internal consistency, test-retest reliability, construct and discriminant validity, and sensitivity to change. However, no investigation of the CIA's factor structure has been carried out using confirmatory factor analysis.

Due to the potential utility of this measure in assessing EDQoL in both clinical and nonclinical samples, further data on the psychometric properties of the CIA are required to 
confirm its usefulness as a measure of functional impairment in EDs. The purpose of the current study is to assess the reliability, validity, and factor structure of the CIA with a clinical sample from a generic treatment service, an area that has been overlooked in studies of the measure thus far.

\section{Methods}

\subsection{Participants and Procedure}

One hundred and ninety consecutive referrals to a specialist adult community ED service were included in the study (178 female; 93.7\%). Following referral, patients attending an initial assessment appointment are asked to complete self-report questionnaires, including those used in the present study. The Eating Disorder Examination (EDE; Fairburn \& Cooper, 1993) is also administered, and demographic data (e.g., weight, height, ethnicity) are also routinely collected. The EDE was administered by non-medical qualified professional staff (nurses, psychologists) who had received training from the instrument's developers. Diagnoses were made on the basis of responses on the EDE, according to DSMIV criteria, although no inter-rater reliability information was available.

The protocol was reviewed by the local NHS Research Ethics Committee and was felt not to be research requiring further review. Measures were completed at assessment (i.e., pre-treatment) between November 2009 and August 2011, and a power calculation based on the suggestions of MacCallum, Browne, and Sugawara (1996) suggested an $N$ of at least 178 to achieve sufficient power.

\subsection{Measures}

2.2.1 The Eating Disorder Examination, $12^{\text {th }}$ edition (EDE; Fairburn \& Cooper, 1993) 
The EDE is an interviewer-administered measure with excellent psychometric properties (Luce \& Crowther, 1999) that is widely used in the assessment of EDs. Aside from generating ED diagnoses, the measure provides information on the frequency of ED behaviours (such as binge eating and purging). It also gives scores on four subscales reflecting the cognitive aspects of ED pathology and provides a Global score indicative of overall psychopathology, ranging from 0-6. Internal consistency (Cronbach's $\alpha$ ) for the EDE subscales were as follows: Restraint: .75, Eating Concern: .57, Weight Concern: .75; Shape Concern: .81; Global: .86.

\subsubsection{The Clinical Impairment Assessment v3.0 (CIA; Bohn \& Fairburn, 2008)}

The self-report CIA is designed to be used in conjunction with other measures of EDs, and asks participants to rate the extent to which problems around eating have interfered with various aspects of life over the preceding 28 days. Responses on a 4-point Likert scale range from 0 ("Not at all") to 3 ("A lot"), and a global score (range = 0-48) can be calculated with a cutoff score $\geq 16$ designed to predict ED case status, although it is not a diagnostic measure (Bohn et al., 2008). Higher scores indicate greater impairment and subscale scores ('personal', 'social', and 'cognitive') can be used to investigate specific areas of impairment.

\subsubsection{The Hospital Anxiety and Depression Scale (HADS; Zigmond \& Snaith, 1983)}

The HADS is a 14-item self-report measure with two subscales assessing symptoms of depression (HADS-D) and anxiety (HADS-A). It is widely used with acceptable psychometric properties (e.g., Bjelland, Dahl, Haug, \& Neckelmann, 2002). In the current study, the HADS-D was used as a covariate in some analyses (e.g., Becker et al., 2010). Cronbach's $\alpha$ in the current sample was .75. 


\subsection{Data Analysis}

Analyses were conducted with SPSS 19.0 and Amos 20.0, and results were interpreted adopting a significance level of $\alpha=0.05$. Confirmatory factor analysis (CFA) was conducted to examine the factor solution of the CIA, using maximum likelihood estimation (based on a covariance matrix and including correlated error terms as appropriate). All results remained significant and the pattern of findings was unchanged when controlling for depression scores and therefore further description of these data is not presented.

\subsubsection{Model fit indices}

Suggested fit indices included a test of overall significance, the relative $\chi^{2}\left(\chi^{2} / d f\right)$, the root mean square error of approximation (RMSEA; Steiger, 1990), measures of incremental fit (CFI; Bentler, 1990, and IFI; De Champlain \& Gessaroli, 1991) and a residuals-based measure (SRMR; Bentler, 1995). Values between 2 and 5 of the relative $\chi^{2}$ indicate acceptable fit (Hooper, Coughlan, \& Mullen, 2008). The RMSEA reflects a measure of approximate fit within a population, and a value around .06 indicates good model fit and around .08 reasonable fit (Hu \& Bentler, 1999), although use of Confidence Intervals (CIs) is recommended (MacCallum et al., 1996). The CFI and IFI compare the hypothesised model to one with poor fit, with acceptable values $\geq 0.90$, and good fit indicated by $\geq 0.95$ (Hu \& Bentler, 1999). An SRMR value $<0.08$ is assumed to be representative of good fit, and 0 indicating perfect fit (Hu \& Bentler, 1999) ${ }^{1}$.

\footnotetext{
${ }^{1}$ It should be noted that problems with goodness-of-fit tests have been discussed (Browne, MacCallum, Kim, Andersen, \& Glaser, 2002).
} 


\section{Results}

Participants were aged $17-60$ years $(M=27.5, \mathrm{SD}=9.89)$ with a mean body mass index $(\mathrm{BMI})$ of $21.5 \mathrm{~kg} / \mathrm{m}^{2}(\mathrm{SD}=6.74$, range $=12.0-61.9)$. Thirty individuals $(15.8 \%)$ met criteria for anorexia nervosa, 55 (28.9\%) for bulimia nervosa, and 82 (43.2\%) for eating disorder not otherwise specified (EDNOS). Twenty-three individuals (12.1\%) were deemed as “subclinical” or having no ED diagnosis. One-hundred and forty-six individuals (76.8\%) described themselves as "White - British," five (2.6\%) as "White - Other," one (0.5\%) as "White - Irish," and one (0.5\%) as “Asian/Asian - British-Indian.” One individual (0.5\%) put themselves as "Any other Ethnic Group," and the remaining 36 (18.9\%) did not provide this information.

\subsection{Confirmatory Factor Analysis}

The overall mean score of the CIA was $34.06(\mathrm{SD}=9.87$, range $=0-48)$ and the sixteen items were submitted to CFA, although non-normal distribution was observed.

Bootstrapping procedures were therefore used to provide standard error estimates that are less biased. Fit indices (see Table 1) indicate adequate fit of the model, with a finding of significance for the relative $\chi^{2}\left(\chi^{2}=236.13(101, p<.001)\right.$. Furthermore, factor loadings were significant, ranging from .49 to $.87(p$ s $<.001)$ and modification indices did not suggest the removal of any items due to cross-loadings.

Table 1

\subsection{Internal consistency}


A measure of internal consistency (Cronbach's $\alpha$ ) demonstrated good subscale reliability for the model; .91 for the global CIA score, .88 for the 'personal' subscale, .84 for 'social', and .82 for 'cognitive'.

\subsection{Validity}

To assess convergent validity, Spearman's correlation coefficients examined the association between EDE scores and global CIA scores. The CIA score was positively associated with Global EDE score $\left(r_{\mathrm{s}}=.62, p<.001\right)$, and its subscales (Restraint $=.42$, Eating Concern $=$ .53 , Shape Concern $=.56$, Weight Concern $=.55, p s<.01)$. Global CIA score was also correlated with measures of depression $\left(r_{\mathrm{s}}=.51, p<.001\right)$ and anxiety $\left(r_{\mathrm{s}}=.50, p<.001\right)$.

As a test of known-groups validity, Global EDE scores were compared using Mann Witney $U$ tests between those scoring above $(n=182 ; 95.8 \%)$ and below the suggested CIA cutoff of 16. Results suggested a significant difference, with a mean (SD) Global EDE score of 4.15 (1.25) for those scoring above the cutoff, compared to 1.39 (1.19) for those scoring below $(z=-4.164, p<.001)$. Those with an eating disorder also scored higher on the CIA than those without (see Table 2).

\section{Table 2}

To assess criterion validity, CIA scores were compared between groups reporting ED behaviours and not. As Table 2 shows, frequencies of binge eating (objective and subjective bulimic episodes) and excessive exercise differed between groups. However, there were no differences in terms of self-induced vomiting or laxative use.

\section{Discussion}

The main aim of this study was to provide further validation of the psychometric properties of the CIA (Bohn \& Fairburn, 2008), a potentially useful measure of impairment resulting from ED pathology. The results extend previous work looking at the psychometric properties of the CIA to a large clinical sample in the UK, using CFA.

The results support the original factor structure proposed by Bohn et al. (2008) and provide further evidence that the CIA is a useful and valid measure of impairment. The 
measure demonstrates good internal consistency, reliability, and validity, and provides a replicable factor structure, demonstrated across a range of different samples. The present study affirms its use in a clinical ED sample.

Some additional findings were noted in the current study. Although those scoring above the cutoff on the CIA reported higher frequency of binge eating and excessive exercise, there was no difference in the frequency of self-induced vomiting or laxative use. Further investigation of the specific effects of ED behaviours (particularly purging) on functional impairment and quality of life is warranted (Jenkins, Hoste, Meyer, \& Blissett, 2011), as Becker et al. (2010) also failed to find differences on these variables, using a similar design to the current study. The CIA scores of individuals without a diagnosis of an ED were also high, although significantly lower than those with an ED. This may be as individuals referred to the service are likely to have difficulties with eating, although perhaps not an eating disorder per se. The wording of the CIA to cover "eating habits" might include individuals with food phobia, for example. As the sample was drawn from a tertiary, specialist ED service, there is likely to be a high degree of comorbidity with other diagnoses, for example those from Axis 2 of the DSM (APA, 2000). Although individuals may not have met criteria for a diagnosis of an ED, they may experience impairment (and thus report this on the CIA) as a result of eating; for example, using restricted eating as a form of selfharm, in the context of borderline personality disorder (e.g., see Zanarini, Reichman, Frankenburg, Reich, \& Fitzmaurice, 2010). However, a further discussion of this is not within the scope of the current study, which was limited by self-report and therefore could not explore questionnaire responses further. Although the study benefits from use of a semistructured interview for the assessment of EDs, no further information was available to support this reliability of the diagnoses made through the EDE. A further limitation was the use of self-report to assess clinical impairment, thus limiting the validity of the assessment of "impairment".

Notwithstanding the identified limitations, the findings presented here, in addition to existing work, indicate that the CIA is a psychometrically sound measure of impairment occurring secondarily to eating disorders. The current study has highlighted some areas for future work, and suggests that, for assessing functional impairment in eating disorders, the CIA is fit for purpose. 


\section{References}

American Psychiatric Association (APA) (2000). Diagnostic and statistical manual of mental disorders. ( $4^{\text {th }}$ ed., Text Revision). Washington, DC: Author.

Becker, A. E., Thomas, J. J., Bainivualiku, A., Richards, L., Navara, K., Roberts, A. L., et al. (2010). Adaptation and evaluation of the Clinical Impairment Assessment to assess disordered eating related distress in an adolescent female ethnic Fijian population. International Journal of Eating Disorders, 43, 179-186.

Bentler, P. M. (1990). Comparative fit indexes in structural models. Psychological Bulletin, 107(2), 238-246.

Bentler, P. M. (1995). EQS structural equations program manual. Encino, CA: Multivariate Software.

Bjelland, I., Dahl, A. A., Haug, T. T., \& Neckelmann, D. (2002). The validity of the Hospital Anxiety and Depression Scale: An updated literature review. Journal of Psychosomatic Research, 52, 69-77.

Bohn, K., \& Fairburn, C. G. (2008). The Clinical Impairment Assessment Questionnaire (CIA 3.0). In C. G. Fairburn (Ed.), Cognitive behaviour therapy and eating disorders (pp. 315-318). New York: Guilford Press.

Bohn, K., Doll, H. A., Cooper, Z., O’Connor, M., Palmer, R. L., \& Fairburn, C. G. (2008). The measurement of impairment due to eating disorder psychopathology. Behaviour Research and Therapy, 46, 1105-1110.

Browne, M. W., MacCallum, R. C., Kim, C.-T., Andersen, B. L., \& Glaser, R. (2002). When fit indices and residuals are incompatible. Psychological Methods, 7(4), 403-421.

De Champlain, A., \& Gessaroli, M. E. (1991). Assessing test dimensionality using an index based on nonlinear factor analysis. Paper presented at the annual AERA meeting, Chicago, IL, April 3-7, 1991.

Engel, S. G., Adair, C. E., Las Hayas, C., \& Abraham, S. (2009). Health-related quality of life and eating disorders: A review and update. International Journal of Eating Disorders, 42, 179-187.

Fairburn, C. G., \& Cooper, Z. (1993). The Eating Disorder Examination (12 $2^{\text {th }}$ Edition). In C. G. Fairburn, \& G. T. Wilson (Eds), Binge eating: nature, assessment and treatment (pp. 317-360). New York: Guilford Press.

Hooper, D., Coughlin, J., \& Mullen, M. (2008). Structural equation modelling: Guidelines for determining model fit. Electronic Journal of Business Research Methods, 6(1), 53-60. 
Hu, L., \& Bentler, P. M. (1999). Cutoff criteria for fit indexes in covariance structure analysis: Conventional criteria versus new alternatives. Structural Equation Modeling: A Multidisciplinary Journal, 6, 1-55.

Jenkins, P. E., Hoste, R. R., Meyer, C., \& Blissett, J. M. (2011). Eating disorders and quality of life: A review of the literature. Clinical Psychology Review, 31, 113-121.

Luce, K. H., \& Crowther, J. H. (1999). The reliability of the eating disorder examinationself-report questionnaire version (EDE-Q). International Journal of Eating Disorders, $25,349-351$.

MacCallum, R. C., Browne, M. W., \& Sugawara, H. M. (1996). Power analysis and determination of sample size for covariance structure modelling. Psychological Methods, 1(2), 130-149.

Reas, D. L., Rø, O., Kapstad, H., \& Lask, B. (2010). Psychometric properties of the Clinical Impairment Assessment: Norms for young adult women. International Journal of Eating Disorders, 43, 72-76.

Steiger, J. H. (1990). Structural model evaluation and modification. Multivariate Behavioral Research, 25, 214-212.

Vannucci, A., Kass, A. E., Sinton, M. M., Aspen, V., Weisman, H., Bailey, J. O., et al. (2012). An examination of the Clinical Impairment Assessment among women at high risk for eating disorder onset. Behaviour Research and Therapy, 50, 407-414. doi: 10.1016/j.brat.2012.02.009

Welch, E., Birgegård, A., Parling, T., \& Ghaderi, A. (2011). Eating disorder examination questionnaire and clinical impairment assessment questionnaire: General population and clinical norms for young adult women in Sweden. Behaviour Research and Therapy, 49, 85-91.

Zanarini, M. C., Reichman, C. A., Frankenburg, F. R., Reich, D. B., \& Fitzmaurice, G. (2010). The course of eating disorders in patients with borderline personality disorder: A 10-year follow-up study. International Journal of Eating Disorders, 43, 226-232.

Zigmond, A. S., \& Snaith, R. P. (1983). The Hospital Anxiety and Depression Scale. Acta Psychiatrica Scandinavica, 67, 361-370. 